\title{
A Numerical ANALYSIS OF THE SINGLE-WELL Steam Assisted Gravity Drainage (SW-SAGd) Process
}

\author{
SUPRI TR - 124
}

By

K. T. Elliot and A. R. Kovscek

\section{TOPICAL REPORT}

\author{
For the period ending \\ June 2001 \\ Work Performed Under Contract No. DE-FC26-00BC15311 \\ Prepared for \\ U.S. Department of Energy \\ Assistant Secretary for Fossil Energy \\ Thomas Reid, Project Manager \\ National Petroleum Technology Office \\ P.O. Box 3628 \\ Tulsa, OK 74101
}




\section{DISCLAIMER}

This report was prepared as an account of work sponsored by an agency of the United States Government. Neither the United States Government nor any agency thereof, nor any of their employees, makes any warranty, express or implied, or assumes any legal liability or responsibility for the accuracy, completeness, or usefulness of any information, apparatus, product, or process disclosed, or represents that its use would not infringe privately owned rights. Reference herein to any specific commercial product, process, or service by trade name, trademark, manufacturer, or otherwise does not necessarily constitute or imply its endorsement, recommendation, or favoring by the United States Government or any agency thereof. The views

and opinions of authors expressed herein do not necessarily state or reflect those of the United States Government or any agency thereof. 


\section{TABLE OF CONTENTS}

$\underline{\text { Page }}$

List of Tables iv

List of Figures

iv

Acknowledgements

V

Abstract

vi

1. Introduction

1

1.1 Problem Definition

3

2. Model Description 3

3. Early-Time Performance Study 5

3.1 Case Studies 6

3.2 Discussion of Early-Time Analysis 9

4. Sensitivity Analysis 9

$\begin{array}{lll}4.1 & \text { Sensitivity cases } & 10\end{array}$

4.2 Discussion of Sensitivity Analysis 12

5. Injector to Producer Spacing 12

6. Conclusions 15

7. Nomenclature 16

8. References 17 


\section{LIST OF TABLES}

$\underline{\text { Page }}$

1. Grid, rock, and oil property description 18

2. Operating conditions for early-time performance study 18

3. Description of sensitivity analysis 19

4. Parameters used to calculate $t_{v} / t_{h} \quad 19$

\section{LIST OF FIGURES}

1. Schematic of grid system: (a) parallel to wellbore and (b) perpendicular to well bore 20

2. Water-oil relative permeability function. 21

3. Gas-liquid relative permeability function. 21

4. Recovery factor for the first year of production. 22

5. Recovery factor for 10 years of production. 23

6. Cumulative steam oil ratio for 10 years of production. 23

7. Steam injection and production history, SAGD from start--Case 1.24

8. Bottomhole pressure, SAGD from start--Case 1. 24

9. Temperature profile at 100 days, SAGD from start--Case $1 . \quad 25$

10. Bottom-hole pressure, extreme pressure differential then SAGD--Case 2. 25

11. Steam injection and pressure history, extreme pressure differential then SAGD--Case 2. 26

12. Temperature profile at 200 days, extreme pressure differential then SAGD--Case 2.26

13. Steam injection and production history, 1 cycle then SAGD--Case 5. 27

14. Bottomhole pressure, 1 cycle then SAGD--Case 5. 27

15. Temperature profile at 200 days, 1 cycle then SAGD--Case 5.

16. Recovery factor versus time, sensitivity analysis. 28

17. Cumulative steam-oil ratio, sensitivity analysis. 29

18. Recovery factor versus time, effect of injector to producer section spacing. 29

19. Cumulative steam-oil ratio, effect of injector to producer section spacing. 30 


\section{ACKNOWLEDGEMENTS}

This paper was prepared with the support of the U.S. Department of Energy, under Award No. DE-FC26-00BC15311. However, any opinions, findings, conclusions, or recommendations expressed herein are those of the authors and do not necessarily reflect the views of DOE. Additionally, the support of the SUPRI-A Industrial Affiliates is gratefully acknowledged. 


\begin{abstract}
Steam assisted gravity drainage (SAGD) is an effective method to produce heavy oil and bitumen which are important energy resources. In a typical SAGD approach, steam is injected into a horizontal well located directly above a horizontal producer helping to displace heated oil. Single-well (SW) SAGD attempts to create a similar process using only one horizontal well. To improve early-time response of SW-SAGD, it is necessary to heat the near-wellbore area to reduce oil viscosity and allow gravity drainage to begin. Ideally heating should occur with minimal circulation or bypassing of steam. We have investigated early-time processes to improve reservoir heating. A numerical simulation study was performed to gauge combinations of cyclic steam injection and steam circulation prior to SAGD in an effort to better understand and improve early-time performance. Results from this study, include cumulative recoveries, temperature distributions, and production rates. It is found that cyclic steaming of the reservoir offers the most favorable option for heating the near-wellbore area to create conditions that improve initial SAGD response. More favorable reservoir conditions such as low viscosity, thick oil zones, and solution gas, improved reservoir response. Under unfavorable conditions, response was limited.
\end{abstract}




\section{INTRODUCTION}

Despite the finite nature of petroleum and gas, they remain dominant primary energy sources for the world as a whole. This appears likely to remain unchanged in the near future (Browne, 1997). In the past, petroleum production has, rightly, focused on the easiest to produce

prospects. With more fields approaching maturity and abandonment, recovery options are required for more difficult to produce reservoirs. Specifically, heavy oil reservoirs hold tremendous petroleum resources that are not utilized to their fullest potential. In the United States alone it is estimated that there are 125 billion barrels of heavy oil (10-20 ${ }^{\circ} \mathrm{API}$ or 940 to 1000 $\mathrm{kg} / \mathrm{m}^{3}$ ) in place (Godec 1991, Mahmood et al. 1995). Worldwide there are also large heavy-oil and bitumen deposits in Canada, Venezuela, China, Indonesia, and the former Soviet Union. Methods are needed to produce effectively heavy oil. One possible option is steam assisted gravity drainage (SAGD).

SAGD maximizes the role of gravity forces during steam flooding of heavy oils. Generally, a pair of horizontal wells is used. As steam enters the reservoir, it heats the reservoir fluids and surrounding rock. Hot oil and condensed water drain though the force of gravity to a production well at the bottom of the formation. In conventional SAGD, steam is injected through a horizontal well placed directly above a horizontal producer. Thus, a steam chamber forms around the injection well. In single-well (SW) SAGD, a horizontal well is completed such that it assumes the role of both injector and producer (Falk et al. 1996). In a typical case, steam is injected at the toe of the well, while hot reservoir fluids are produced at the heel of the well. Recovery mechanisms are envisioned to be similar to conventional SAGD. Advantages of SWSAGD might include cost savings in drilling and completion and utility in relatively thin reservoirs where it is not possible to drill two vertically spaced horizontal wells. However, the process is technically challenging.

In a reservoir where cold oil is very viscous and will not flow easily, initial production rates via any gravity drainage process are very small. In a strict definition of SAGD, steam only enters the reservoir to fill void space left by produced oil. If the oil is cold, we must heat it to reduce viscosity. Therefore, initial heating of the area around the wellbore is required so that 
SAGD can take place. After SAGD is initiated, a steam chamber will grow upward to the top of the reservoir and then begin to extend horizontally (Butler 1991). At the steam-chamber boundary, steam condenses as heat is transferred to the oil. Condensed water and hot oil flow along the steam chamber to the production well (Butler 1991).

Joshi (1986) found experimentally that under various injection-production well configurations, the steam chamber grows to cover a majority of the reservoir and the recovery efficiency is very good in all cases. Therefore, we expect that early-time production results from SW-SAGD may vary from the conventional approach, but at late times, we expect similar recovery efficiencies. Oballa and Buchanan (1996) simulated various scenarios to evaluate the difference between cyclic steam injection and SAGD. They focused, partially, on the interactions between the reservoir, the well completion, and the recovery of oil. It was concluded that the drainage process may be feasible provided that a proper operating strategy is identified. Additionally, Shen (2000) pointed out via simulation that a dilated zone with enhanced permeability around the well accelerates fluid exchange between the well and the field.

Field tests of SW-SAGD are not extensively documented in the literature. Falk et al. (1996) overview the completion strategy and some typical results for a project in the Cactus Lake Field, Alberta Canada. A roughly $850 \mathrm{~m}$ long well was installed in a region with 12 to $16 \mathrm{~m}$ of net pay to produce $12^{\circ} \mathrm{API}$ gravity oil. The reservoir is a clean, unconsolidated, sand with 3400 md permeability. Apparently, no attempts were made to preheat the reservoir before initiation of SW-SAGD. Steam was injected into the cold reservoir at the toe of the well and oil produced at the heel. Oil production response to steam was slow and gradually increased to more than 100 $\mathrm{m}^{3} / \mathrm{d}$. The cumulative steam-oil ratio was between 1 and 1.5 for the roughly one-half year of reported data.

McCormack et al. (1997) also describe operating experience with nineteen SW-SAGD installations. Performance for approximately two years of production was mixed. Of their seven pilot projects, five were either suspended or converted to other production techniques because of poor production. Positive results were seen in fields with relatively high reservoir pressure, relatively low oil viscosity, significant primary production by heavy-oil solution gas drive, and/or insignificant bottom-water drive. Poor results were seen in fields with high initial oil viscosity, strong bottom-water drive, and/or sand production problems. Although the authors note that the 
production mechanism is not clearly understood, they suspect that the it is a mixture of gravity drainage, increased primary recovery because of near-wellbore heating via conduction, and hot water induced drive/drainage.

\subsection{Problem Definition}

This paper is grouped into two general topics: (i) a screening study of early time operating performance of SW-SAGD and (ii) a sensitivity analysis of the effect of reservoir and well completion parameters. Understanding the operating conditions to improve initial performance relates directly to understanding methods of heating the near-wellbore area at early-time. A central idea realized here is that the near-well region must be heated rapidly and efficiently for significant early-time response. The sensitivity analysis helps us understand reservoir properties, fluid conditions, and well completion strategies where the process might be an appropriate production technique.

To gain an understanding of early-time performance, we build and compare various computer simulations. The processes examined include cyclic steaming, steam circulation within the well, and an extreme pressure differential between the injection and production sections of the well. Each initial operating period was followed by SAGD; that is, continuous steam injection and oil production with little net injection of steam. For the sensitivity analysis, we compared a base case against runs in which we varied oil viscosity and gas content, reservoir height, permeability anisotropy, and finally the well completion. Computer Modeling Group's (CMG) STARS thermal simulator was used to perform all of the work.

\section{MODEL DESCRIPTION}

The base case is STARS (CMG 1998) example sthrw009.dat released with Version 98.01. Reservoir and fluid properties represent a typical Alberta reservoir. The operating conditions and well completion were modified to develop additional cases.

The grid system and dimensions are illustrated in Figure 1. Figure 1a displays the cross section along the length of the well and Fig. $1 \mathrm{~b}$ a cross section perpendicular to the well. The grid system is Cartesian with local grid refinement, as detailed in Fig. 1, immediately around the 800 $\mathrm{m}$ long well. An element of symmetry, with one boundary lying along the wellbore, is used to 
represent the reservoir volume. We assume that wells will be developed in multiple patterns and thus all boundaries are no flux. The well spacing is $160 \mathrm{~m}$. The single horizontal well is represented using a discretized wellbore model that accurately represents fluid and heat transfer in the well (CMG 1998). Additionally, the well is broken into two sections to simulate the placement of a packer. Each section is equal in length and they lie directly end to end. This gives us freedom to explore various completion strategies and operating conditions. Our initial simulation work suggested that this inject at the toe and produce at the heel strategy had greater probability of success than attempting to develop countercurrent steam and oil flow along the entire length of the well. Additionally, Shen (2000) surmised that macroscopic co-current circulation is a dominant fluid exchange pattern between the well and the reservoir. Table 1 lists the exact dimensions of the reservoir model, grid-block information, and reservoir properties. Initially, the average reservoir pressure is $2,654 \mathrm{kPa}(380 \mathrm{psi})$, the pressure distribution is hydrostatic, and the initial reservoir temperature is $16^{\circ} \mathrm{C}$.

The water-oil relative permeability and gas-liquid relative permeability functions are displayed graphically in Figures 2 and 3, respectively. Table 1 also lists the initial fluid saturations of the reservoir. The homogeneous porosity is $33 \%$. The horizontal permeability, $\mathrm{k}_{\mathrm{h}}$, is $3400 \mathrm{md}$, whereas the vertical permeability, $\mathrm{k}_{\mathrm{v}}$, is $680 \mathrm{md}$. Hence, the ratio $\mathrm{k}_{\mathrm{h}}: \mathrm{k}_{\mathrm{v}}$ is about 5 to 1.

A live, black-oil model is used. The initial oil phase is made up of $90 \%$ by mole oil component and $10 \%$ by mole gas component for a solution gas-oil ratio (GOR) of about 28 SCF/STB. The effect of solution GOR on oil recovery is explored in the sensitivity analysis. The oil viscosity versus temperature relationship is given in Table 1, and the oil viscosity at the initial reservoir temperature is $4.043 \mathrm{~Pa}-\mathrm{s}(4043 \mathrm{cP})$. An increase of oil temperature to $100{ }^{\circ} \mathrm{C}$ decreases the oil viscosity to $0.030 \mathrm{~Pa}-\mathrm{s}(30 \mathrm{cP})$.

Table 2 lists the operating constraints for the four base cases created to explore a range of early-time procedures. Briefly the cases represent SAGD operating conditions, extreme pressure differential conditions where steam is injected near the fracturing or parting pressure of the formation, cyclic steam injection, and steam circulation through the well. For a maximum injection pressure of $10,000 \mathrm{kPa}$, as reported in Table 2, the reservoir depth would have to be greater than roughly $450 \mathrm{~m}$ to avoid fracturing, assuming that overburden pressure increases at 
$22.6 \mathrm{kPa} / \mathrm{m}$. Similar maximum pressures have been reported in the field (Liderth 1995). Arbitrarily, $100 \mathrm{~d}$ was chosen as the duration of attempts to heat the near-well region. In all cases, SAGD conditions follow this initial period. Each of the constraints will be discussed in more detail below.

\section{EARLY-TIME PERFORMANCE STUDY}

To heat the near-wellbore area and improve the initial production response of SAGD, we combined the operating conditions displayed in Table 2 into seven cases: (i) SAGD operation conditions from the start, (ii) extreme pressure differential between injector and producer sections for 100 days followed by SAGD, (iii) steam circulation for 100 days followed by SAGD, (iv) circulate for 100 days followed by 100 days of an extreme pressure differential followed by SAGD, (v) cycle once followed by SAGD, (vi) cycle twice followed by SAGD, and (vii) cycle three times followed by SAGD. In each case except the first, an initial preheating phase precedes SAGD.

Results of this screening study are displayed in Figures 4 to 6 . Figures 4 and 5 display recovery factor histories for the first year of production and for 10 years of production, respectively. Recovery factor refers to the fraction of oil produced from the entire simulation volume including the $600 \mathrm{~m}$ of reservoir beyond the toe of the well. The cumulative steam oil ratio (CSOR) versus time curves for each case are displayed in Fig. 6. It is obvious from the curves that it is possible to improve initial production response. In general, cyclic steaming as applied in Cases 5 to 7 leads to the most rapid oil recovery. However, the late time recovery performances shown in Fig. 5 display similar behavior for all cases. Recovery factor ranges from 19-22\% after 3650 days of injection and all curves increase at similar rates.

Case 1 represents a base case in which SAGD was initiated from the beginning without preheating. This case produced the lowest percent recovery curve. In Case 2, we increase the injection rate constraint which thereby increases the pressure differential between the injection and production wells; hence, the conditions are referred to as extreme. The pressurization of the system improves production somewhat relative to the base case.

The 'circulate' phase in Cases 3 and 4 is a modified form of steam circulation in the well. Steam is injected so as to maintain the initial reservoir pressure. We did not simulate true steam 
circulation where steam that exits the tubing may only flow in the well before it is produced. A true circulating case in which the near-wellbore area is heated only by conduction would be inefficient, and the other techniques that we explore present better options. Circulation here is similar to the SAGD case: steam may replace oil volume in the reservoir when oil is produced.

The cumulative steam oil ratio displayed in Fig. 6 is standard: the cumulative steam volume injected as cold water equivalent volume divided by the cumulative hydrocarbon production. The CSOR varies substantially among the studies during the initial period because significantly different production and injection schemes were used. At late time, however, the CSOR for all cases averages roughly 3.0. Note, however, that the cyclic cases perform somewhat better, with regard to CSOR, in initial and late-time response.

\subsection{Case Studies}

Three of the cases above will be examined in greater detail to explain the differences in oil recovery and heating of the reservoir volume. The reference continuous SW-SAGD, extreme pressure differential, and one cycle prior to SW-SAGD cases will be discussed. Production rates, well pressures, and temperature profiles around the well will be examined.

Case 1,Continuous SAGD. In Case 1 we operate immediately at SAGD conditions and do not include a preheat phase. Figure 7 displays the injection and production curves for Case 1. The darkest curve in Fig. 7 represents the oil production rate. As expected, the initial oil rate is low, but increases with time as a steam chamber slowly develops and more oil is heated. Oil production peaks at roughly $80 \mathrm{~m}^{3} /$ day.

Note that our "SAGD" case is actually a combination of SAGD and pressure draw-down. Production well conditions are such that reservoir pressure must decline. It is clear from the similarity between the steam injection rate and water production rate in Fig. 7 that steam shortcircuits from the injection region to the production region and the contact time is short between steam and reservoir. Recall that we represent the horizontal well with two separate sections placed end to end. The pressure differential between the regions and the proximity of "injection" and "production" perforations causes steam to travel quickly between them. Albeit inefficiently, a steam chamber is created within the reservoir as heated oil drains to the production region and 
steam migrates up to fill the void space. Optimizing the effect of spacing between injection and production sections represents another interesting problem to be addressed below.

Figure 8 displays bottom-hole pressure curves for injection and production in Case 1. A large pressure differential of about $3000 \mathrm{kPa}$ exists initially between the two sections of the well. Over time, the reservoir pressure decreases because we produce more fluids than we inject. This also causes the injection pressure to decrease. Figure 9 displays a temperature profile at 100 days for Case 1. Light shading corresponds to high temperature, and dark shading to low temperature. At late times, a large steam chamber grows in the middle region of the system. At 100 days, however, the steam chamber is just beginning to grow above the area between the injection and production sections. It is important to maximize the amount of net heat injection into the reservoir at early times to maximize the size of the heated volume surrounding the wellbore.

Case 2, Extreme Pressure Differential Prior to SAGD. In the extreme pressure differential case, the injection rate constraint is increased and this increases the pressure differential between the injection and production wells. Figure 10 displays the bottom-hole pressure histories. For the first 100 days, steam is injected at roughly $7000 \mathrm{kPa}$ forcing steam into the formation and increasing the average reservoir pressure. Figure 11 displays the production response for the extreme period in the first 100 days followed by SAGD. Observing the oil rate in the first 100 days and comparing to Fig. 7, we see that the oil rate ramps up faster than Case 1. This is logical because Case 2 is an accelerated version of SAGD.

Figure 10 also indicates that a very high injection bottom-hole pressure is obtained between 0 and 100 days. High pressure results because the water production rate is substantially less than the steam injection rate, as shown in Fig. 11. Under the given conditions a limited amount of steam short-circuits, and an appreciable amount of steam enters the reservoir and increases the reservoir pressure. Pressure does not exceed the critical pressure where the formation parts or fractures.

If we view the oil production rate in Fig. 11 during and after the extreme period, it is obvious that we have improved response. Direct comparison of Cases 2 and 1 is somewhat misleading. Injection conditions have led to high reservoir pressure at the beginning of SAGD, causing significant production through pressure depletion in addition to gravity drainage of heated reservoir fluids. A better comparison is the temperature profile along the length of the 
well displayed in Figure 12. The profile represents a relative time similar to the Case 1 profile, 100 days after SAGD inception. Again, light shading is high temperature and dark shading is low temperature. The profile for Case 2 is much more favorable. There is a larger heated area with a larger steam chamber. The steam chamber forms in the middle of the well because pressure drawdown is large; thus, the steam flux is largest in this location.

Case 5, One Cycle Prior to SAGD. Our cyclic case is very similar to typical cyclic conditions common in many thermal recovery operations. We inject steam along the entire well for 50 days, let it soak for 10 days, then produce along the entire length of the well for 60 days. The injection and production profiles in Figure 13 summarize this cycle of steam injection, shut in, production followed by SAGD.

Figure 14 shows that the bottom-hole pressure increases to about $8000 \mathrm{kPa}$ during the cyclic phase, but still remains within a feasible range. Because the oil is very viscous, this energy is depleted rapidly from the reservoir when production begins. From the oil production rate after the cycling period in Fig. 13, it is again obvious that SAGD response is improved. The slow increase of production rate found in Case 1, Fig. 7, is not evident here. The minimum production rate at roughly 200 days occurs because reservoir pressure is depleted somewhat following the cyclic period, as shown by the plot of well bottom hole pressure in Fig. 13. Again, the maximum oil production rate is about $80 \mathrm{~m}^{3} /$ day. In this case, the reservoir pressure at SAGD inception is similar to that in Case 1. We conclude that SAGD performs better because the near-wellbore area is heated.

Figure 15 displays the temperature profile at 120 days following SAGD inception. The temperature distribution is more uniform along the entire wellbore. Also, a large steam chamber is growing in the area immediately above the injection/production section. Additionally, the shading indicates that the entire horizontal length of the well has been heated somewhat. Hence, the rapid production response displayed in Fig. 14. Also, by comparing Figs. 15 and 12, it is apparent that the heated zone is larger than Case 2.

Contrary to the extreme pressure differential and SAGD cases where short-circuiting caused much of the steam to exit the reservoir immediately, the cyclic case is more efficient. All of the injected steam enters the reservoir and heats the near-wellbore area. One consequence of this is the uniform temperature distribution along the entire wellbore. Because of the increased 
thermal efficiency of the cyclic process, it appears that this procedure is the most appealing method of initiating SAGD.

\subsection{Discussion of Early-Time Analysis}

The problem of improving early-time performance of SW-SAGD transforms, essentially, into a problem of heating rapidly the near-wellbore area to create conditions that allow gravity drainage of oil. More specifically, for a steam chamber to grow, oil viscosity must be low enough so that fluid drains creating voidage for steam to fill. After the conditions necessary for gravity drainage of oil have been initiated by preheating, the SW-SAGD process allows for continuous steam chamber growth and oil production. Comparing the various simulation results, cyclic steam injection appears to be the most efficient method of heating the near-wellbore area. Heating is much more rapid than relying on conduction alone.

An important general observation is that regardless of the process, early-time procedures should be carried out to maximize steam injection and heat delivery to the reservoir. The goal of any early-time procedure should be to heat the near-wellbore area as uniformly as possible. This goal is easier to achieve when operating at a maximum steam temperature. Later in the SAGD process, pressure can and should be reduced to a target operating pressure which optimizes efficiency and production rate.

The late time performance for all of the cases is favorable regardless of the early-time process. This confirms Joshi's finding that a steam chamber will grow in the reservoir. Favorable recovery factors are obtainable regardless of the injection/ production configuration (Joshi 1986).

There are obvious factors that will improve or inhibit SW-SAGD performance. For example, lower viscosity will certainly improve response, as will larger rock permeability and system compressibility. The actual variance in performance due to differing reservoir parameters is an interesting problem that we begin to address using a sensitivity analysis in the next section. 


\section{SENSITIVITY ANALYSIS}

We performed a sensitivity analysis of various reservoir parameters to gain a better understanding of their effect on production performance. Oil viscosity and gas content, reservoir thickness, and horizontal to vertical permeability anisotropy were studied.

The sensitivity analysis base case varies slightly from the base case used in the early-time analysis. Table 3 displays the operating conditions for the sensitivity analysis base case. The base case consists of two steam injection cycles followed by SAGD operating conditions. We adjusted the operating conditions in an attempt to reduce steam short-circuiting, reduce steam-oil ratio, and to improve efficiency. During the initial cyclic period, we reduced the maximum reservoir pressure to $8,000 \mathrm{kPa}$ from $10,000 \mathrm{kPa}$ while keeping the rest of the operating conditions the same. The steam injection temperature was $296{ }^{\circ} \mathrm{C}$, which corresponds to a steam pressure of $8004 \mathrm{kPa}$. During SAGD, operating conditions were chosen so that the process operated near the original reservoir pressure of $2654 \mathrm{kPa}$. Maximum injection pressure was set slightly above initial reservoir pressure at $3230 \mathrm{kPa}$; minimum production pressure was set slightly below initial reservoir pressure at $2230 \mathrm{kPa}$. The steam injection temperature was reduced to $238^{\circ} \mathrm{C}$ from 295 ${ }^{\circ} \mathrm{C}$. Recall that initial reservoir conditions were chosen to approximate field conditions (Oballa and Buchanan 1996). The rate constraints remained the same at $300 \mathrm{~m}^{3} / \mathrm{d}$ maximum liquid production and $200 \mathrm{~m}^{3} / \mathrm{d}$ maximum steam injection rate.

Between the injection and production sections of the horizontal well, a $30 \mathrm{~m}$ long unperforated section was added. This is an attempt to force steam to penetrate substantially far into the reservoir and reduce the amount of steam short-circuiting.

\subsection{Sensitivity Cases}

The various cases created in the sensitivity analysis include: (i) a base case with the properties in Table 1 and operating conditions shown in Table 3, (ii) dead oil to examine the effect of solution gas, (iii) an increase in pay thickness to $28 \mathrm{~m}$, (iv) a reduction in pay thickess to $4 \mathrm{~m}$, (v) permeability anisotropy $\mathrm{k}_{\mathrm{h}}: \mathrm{k}_{\mathrm{v}}$ of 1 , (vi) $\mathrm{k}_{\mathrm{h}}: \mathrm{k}_{\mathrm{v}}$ equal to 2 , (vii) $\mathrm{k}_{\mathrm{h}}: \mathrm{k}_{\mathrm{v}}$ equal to 10 , (viii) oil viscosity of $20 \mathrm{~Pa}-\mathrm{s}$ at initial reservoir temperature (20,000 cP), and (iv) oil viscosity of $40 \mathrm{~Pa}-\mathrm{s}$ $(40,000 \mathrm{cP})$ at initial reservoir temperature. The viscosity versus temperature relation for the base case is given in Table 1 and those for the 20 and $40 \mathrm{~Pa}$-s cases are listed in Table 3. 
All calculations in the sensitivity cases include a separation of $30 \mathrm{~m}$ between injector and producer sections of the well to achieve better steam distribution in the reservoir. Two periods of cyclic steam injection precede continuous injection and production. In both periods, steam is injected for 50 days at a rate of $300 \mathrm{~m}^{3} /$ day with a maximum allowed pressure of $8000 \mathrm{kPa}$. The soak period is 10 days and the length of production is a relatively short 40 days to avoid large heat withdrawal from the reservoir. Continuous SAGD operating conditions follow. All of the various sensitivity runs follow this procedure.

The recovery factor versus time and cumulative steam-oil ratio (CSOR) versus time curves are presented in Figures 16 and 17, respectively. Again, recovery refers to the entire simulation volume. Significant variation is found in production response between most of the cases. Briefly, production is highest when the reservoir permeability is isotropic, and is worst when the initial oil viscosity is high or the oil-saturated thickness is small. The steam-oil ratio is largest for the short formation thickness of $4 \mathrm{~m}$. The next largest CSOR is for the viscous $40 \mathrm{~Pa}-\mathrm{s}$ initial oil case. The smallest CSOR is found for the case with a pay zone thickness of $28 \mathrm{~m}$ and for cases where $\mathrm{k}_{\mathrm{h}}: \mathrm{k}_{\mathrm{v}}$ approaches 1 . Note that recovery factors are less here, Fig. 16, compared to the early-time study, Fig. 5, because the steam injection pressure has been reduced substantially as seen by comparing Tables 2 and 3 .

Due to space restrictions, it is impossible to display the instantaneous production rates, bottomhole pressure, and temperature profiles for all of the sensitivity cases. However, a brief discussion of the results of each of the sensitivity cases will be given.

The base case oil viscosity is $4.043 \mathrm{~Pa}-\mathrm{s}$ at initial reservoir conditions. Two additional cases were created by increasing the initial viscosity to $20 \mathrm{~Pa}-\mathrm{s}$ and then $40 \mathrm{~Pa}$-s. The recovery factors at 3650 days (10 years) for these two less favorable cases were $4.5 \%$ and $2.7 \%$, respectively, as compared to $10.6 \%$ for the base case. The cumulative steam-oil ratios were also unfavorable. The CSOR were 3.7 and 4.8 after 10 years for the 20 and 40 Pa-s cases, respectively. The problem is quite simple: it is hard for the viscous oil to drain and therefore it cannot be replaced by steam. In the base case, the average oil production rate is $75 \mathrm{~m}^{3} /$ day over the 3650 days of production and excluding the startup period. For the $20 \mathrm{~Pa}-\mathrm{s}$ case the average oil production rate is $30 \mathrm{~m}^{3} /$ day while for the $40 \mathrm{~Pa}-\mathrm{s}$ case it is $20 \mathrm{~m}^{3} /$ day. As the viscosity increases 
the average oil production rate decreases, it becomes difficult to meet the steam injection target, and the size of the steam chamber is smaller compared to the less viscous cases.

The base horizontal to vertical permeability ratio, $\mathrm{k}_{\mathrm{h}}: \mathrm{k}_{\mathrm{v}}$, is 4.25 . The vertical permeability was adjusted to create three more cases with ratios of 1,2 , and 10 . In all cases, the horizontal permeability remained fixed at $3400 \mathrm{mD}$. Larger ratios present less favorable conditions for upward steam migration and oil drainage. As $\mathrm{k}_{\mathrm{h}}: \mathrm{k}_{\mathrm{v}}$ increases, cumulative recovery at a given time decreases and the CSOR increases, as shown in Figs. 16 and 17.

The base case oil composition contained $10 \%$ gas by mole which translates to a solution gas oil ratio of about $28 \mathrm{SCF} / \mathrm{STB}$. An additional case that models a dead oil was created by reducing the solution gas to $1 \%$ by mole. The two effects of solution gas in regard to the oil phase are to increase oil-phase compressibility and reduce the oil-phase viscosity. Oil phase viscosity is computed as a mole fraction weighted sum of the oil and gas component viscosities (CMG 1998). Recovery factor and CSOR were less favorable with the dead oil at $9.2 \%$ and 3.0 after 10 years as compared to $10.4 \%$ and 2.8 for the base case. Likewise, the average oil production rate is $64 \mathrm{~m}^{3} /$ day over the ten year period as compared to $80 \mathrm{~m}^{3} /$ day for the base case.

\subsection{Discussion of Sensitivity Analysis}

Taken together, the results from the sensitivity analysis suggest that application of SWSAGD to exceptionally viscous oils will be difficult. When the initial viscosity is greater than 10 Pa-s, oil drainage becomes very slow and it is difficult to form a large steam chamber. Likewise, the application of SW-SAGD to thin oil zones with thickness of roughly $4 \mathrm{~m}$ does not appear to be feasible. A steam chamber of significant height must develop for efficient oil drainage. On the other hand, the 19.6 and $28 \mathrm{~m}$ thick cases showed significant recovery and little difference was found between theses two cases.

The presence of solution gas also aids recovery somewhat. Even though the oil is viscous and the amount of gas low in both cases, volumetric expansion of the oil is aided by solution gas and cumulative recovery increases by $10 \%$ relative to the dead oil case at 3650 days.

As expected, oil recovery improves as the permeability anisotropy decreases. Both steam injection and oil drainage are aided as the vertical permeability increases relative to the 
horizontal. Resistance to flow in the vertical direction decreases relative to horizontal. Additionally, less short circuiting occurs as $\mathrm{k}_{\mathrm{v}}$ increases relative to $\mathrm{k}_{\mathrm{h}}$.

\section{INJECTOR TO PRODUCER SPACING}

In all of the runs in the sensitivity analysis, $30 \mathrm{~m}$ of unperforated well separated injection and production regions. Separating the regions further increases the length of time required for steam to flow from the injection to the production section and thereby improves growth of the steam chamber. However, separation between injection and production regions delays oil production.

To quantify the effect of separating injection and production regions, we performed the following highly approximate analysis. The Darcy velocity of a particle or volume of steam $\left(u_{v}\right)$ flowing upward above the horizontal injection section is given by

$$
\mathrm{u}_{\mathrm{v}}=-\frac{\mathrm{k}_{\mathrm{v}} \mathrm{k}_{\mathrm{rs}}}{\mu_{\mathrm{s}}} \Delta \rho \mathrm{g}
$$

where $\mathrm{k}_{\mathrm{v}}$ is the vertical permeability, $\mathrm{k}_{\mathrm{rs}}$ is the relative permeability to steam, $\mu_{\mathrm{s}}$ is the steam viscosity, $\Delta \mathrm{p}$ is the density difference between the oil and steam, and $\mathrm{g}$ is the acceleration due to gravity. The Darcy velocity in the horizontal direction $\left(\mathrm{u}_{\mathrm{h}}\right)$ between the injection and production regions is given by

$$
u_{h}=-\frac{k_{h} k_{r s}}{\mu_{s}} \frac{d p}{d x}
$$

where $\mathrm{k}_{\mathrm{h}}$ is the horizontal permeability and $\mathrm{dp} / \mathrm{dx}$ is the pressure gradient in the horizontal direction.

The characteristic times required for a particle to travel to the top of the reservoir $\left(\mathrm{t}_{\mathrm{v}}\right)$ and from the injection section to the production section $\left(\mathrm{t}_{\mathrm{h}}\right)$ are given by

$$
\mathrm{t}_{\mathrm{v}}=\frac{\mathrm{h}}{\mathrm{u}_{\mathrm{v}}}
$$

and

$$
\mathrm{t}_{\mathrm{h}}=\frac{\mathrm{L}}{\mathrm{u}_{\mathrm{h}}}
$$


where $\mathrm{h}$ is the height of the reservoir and $\mathrm{L}$ is the distance between injection and production regions. If the $\mathrm{t}_{\mathrm{v}}: \mathrm{t}_{\mathrm{h}}$ ratio is larger than one, then the time required for a particle to travel to the top of the reservoir is larger than the time required to travel to the production section. Therefore, we expect a large amount of steam short-circuiting. Conversely, if the $t_{\mathrm{v}}: \mathrm{t}_{\mathrm{h}}$ is close to 1 , we would expect limited steam short-circuiting, better steam flow through the reservoir, and increased steam chamber growth.

Substituting the Darcy velocity equations into the characteristic time equations and simplifying allows us to calculate the ratio in terms of available parameters

$$
\frac{\mathrm{t}_{\mathrm{v}}}{\mathrm{t}_{\mathrm{h}}}=\frac{\mathrm{h}}{\mathrm{L}} \frac{\mathrm{k}_{\mathrm{h}}}{\mathrm{k}_{\mathrm{v}}} \frac{\frac{\mathrm{dp}}{\mathrm{dx}}}{\Delta \rho \mathrm{g}}
$$

We approximate $\mathrm{dp} / \mathrm{dx}$ as,

$$
\frac{\mathrm{dp}}{\mathrm{dx}} \tilde{\mathrm{n}} \frac{\Delta \mathrm{p}}{\mathrm{L}}=\frac{\mathrm{p}_{\mathrm{inj}}-\mathrm{p}_{\text {prod }}}{\mathrm{L}}
$$

The subscripts inj and prod refer to injection and production pressure. Substituting this into Eq. 5 yields

$$
\frac{\mathrm{t}_{\mathrm{v}}}{\mathrm{t}_{\mathrm{h}}}=\frac{\mathrm{h}}{\mathrm{L}^{2}} \frac{\mathrm{k}_{\mathrm{h}}}{\mathrm{k}_{\mathrm{v}}} \frac{\left(\mathrm{p}_{\text {inj }}-\mathrm{p}_{\text {prod }}\right)}{\Delta \rho \mathrm{g}}
$$

For the base case of the sensitivity analysis and using the properties displayed in Table 4, we calculate a $t_{v}: t_{h}$ value of 12 . Therefore, we do not expect steam to have a strong tendency to flow upward. Although this analysis is just an approximation, it does help us to estimate if shortcircuiting will be an immediate production problem. A more thorough analysis would consider variations in temperature, pressure, density, and viscosity as well as a more complete description of the pressure distribution.

To gauge the effect of greater distance between the injection and production regions, additional simulations were conducted using the properties of the base case for the sensitivity analysis, Table 3. As previously, two cycles of steam stimulation preceded continuous steam injection. Separation sizes of 60, 90, and $120 \mathrm{~m}$ were examined. These distances correspond to $\mathrm{t}_{\mathrm{v}}: \mathrm{t}_{\mathrm{h}}$ of $3.0,1.3$, and 0.75 , respectively. In all cases, the length of the injection and production regions is the same only the distance between the two changes. 
Recovery factor and CSOR histories for these calculations are given in Figures 18 and 19. The general trend over 3650 days is that recovery decreases as the injection to production region spacing increases. The recovery factor for the $30 \mathrm{~m}$ separation distance is $10.4 \%$ after 3650 days whereas that for the $90 \mathrm{~m}$ separation is $9.7 \%$. On the other hand, the CSOR decreases only slightly as the separation size increases. This indicates that recovery efficiency has not increased greatly with the addition of unperforated well between the injection and production regions.

Throughout, we have specified equal lengths of injection and production regions of the well for simplicity. In practice, this is both unnecessary and unlikely to be the case. It is probable that the injection region could be shortened considerably thereby devoting a greater portion of the well to production. As steam is much less viscous and dense than the oil, steam mobility is large. Thus, it should be possible to distribute steam in the reservoir and develop a steam chamber over the horizontal well with a much smaller perforated section provided that steam short circuiting from injector to producer regions is minor. We do not attempt such an analysis here.

\section{CONCLUSIONS}

Here it is shown that to improve early-time performance of SW-SAGD, it is necessary to heat the near-wellbore region rapidly and uniformly to reduce oil viscosity and promote gravity drainage. Cyclic steaming, as a predecessor to SW-SAGD, represents the most thermally efficient early-time heating method. Uniform heating along the length of the wellbore appears achievable with cyclic steam injection. Immediately placing a cold well on SAGD hinders the early-time heating process and initial production response in this case will be low. Regardless of the earlytime process, it should be performed to provide maximum heat delivery to the reservoir. Additionally, despite different initial procedures, the oil production rates after several years of steam injection are all very similar.

The sensitivity analysis performed here indicates that SW-SAGD is most applicable to heavy oils with initial viscosity below $10 \mathrm{~Pa}-\mathrm{s}$ (10,000 cP) Additionally, the reservoir must be sufficiently thick to allow significant vertical steam chamber growth. Recovery from thin oil zones is not significant or efficient. The sensitivity analysis also indicates that the presence of 
relatively small amounts of solution gas aids the recovery process by enhancing volumetric expansion of the oil on heating.

A simplified analysis was completed to examine the effect of increasing the distance between regions of the well dedicated to injection and production. The cumulative steam-oil ratio did not decrease substantially with increased separation indicating that this strategy does not enhance steam chamber growth or recovery efficiency, contrary to the results of the analysis.

\section{NOMENCLATURE}

$\begin{array}{ll}\text { CWE } & \text { cold water equivalent } \\ \mathrm{g} & \text { acceleration due to gravity } \\ \mathrm{h} & \text { net reservoir height } \\ \mathrm{k} & \text { permeability } \\ \mathrm{kr} & \text { relative permeability } \\ \mathrm{L} & \text { distance between injection and production regions } \\ \mathrm{p} & \text { pressure } \\ \mathrm{t} & \text { characteristic time } \\ \mathrm{u} & \text { Darcy velocity } \\ \mathrm{X} & \text { distance }\end{array}$

$\underline{\text { Greek }}$

$\mu \quad$ viscosity

$\mathrm{p} \quad$ phase density

\section{$\underline{\text { Subscripts }}$}

$\begin{array}{ll}\text { h } & \text { horizontal } \\ \text { s } & \text { steam } \\ \text { v } & \text { vertical }\end{array}$




\section{REFERENCES}

1. Browne, J. 1997. "Responding to Global Climate Change." Speech, Stanford University, Stanford, CA. May 19.

2. Butler, R. M. 1991. Thermal Recovery of Oil and Bitumen. Prentice-Hall, Englewood Cliffs, NJ U.S.A. p. 285-359.

3. Computer Modelling Group LTD. 1998. STARS Version 98 User's Guide. CMG Calgary, Alberta, Canada.

4. Falk, K., Nzekwu, B., Karpuk, B., and Pelensky, P. 1996 World Oil. July: 85-95.

5. Godec, M. L. 1991. "Characterization and Potential of U.S. Heavy Oil." Proceedings of the 5th UNITAR International Conference on Heavy Crude Oil and Tar Sands, Caracas, Venezuela, Aug. 4-9.

6. Joshi, S. D. 1986. A Laboratory Study of Thermal Oil Recovery Using Horizontal Wells. SPE 21751Proceedings of the SPE/DOE Fifth Symposium on Enhanced Oil Recovery, Tulsa, OK, Apr. 20-23.

7. Liderth, D. 1995. Daily Oil Bulletin, May 2, 1995.

8. McCormack, M., Fitzgibbon, J., and Horbachewski, N. 1997. Review of Single-Well SAGD Field Operating Experience. Canadian Petroleum Society Publication, No. 97-191.

9. Mahmood, S. M., Olsen, D. K., and Thomas, C. P. 1995. Heavy Oil Production from Alaska. Proceedings of the 6th UNITAR International Conference on Heavy Crude Oil and Tar Sands, Houston, TX, Feb. 12-17.

10. Oballa, V. and Buchanan, W. L. 1996. Single Horizontal Well In Thermal Oil Recovery Processes. SPE 37115. Proceedings of the SPE International Conference on Horizontal Well Technology, Calgary, Alberta Canada, Nov. 18-20.

11. Shen, C. 2000. J. Can. Pet. Tech. 38 :24-30. 
Table 1: Grid, rock, and oil property description.

\begin{tabular}{|c|c|c|c|}
\hline \multicolumn{2}{|c|}{ Grid System } & \multicolumn{2}{|c|}{ Rock Properties } \\
\hline total no. blocks & 5,568 & porosity & $33 \%$ \\
\hline $\mathrm{x}$-dimension & $1,400 \mathrm{~m}$ & $\mathrm{k}_{\mathrm{h}}$ & $3,400 \mathrm{mD}$ \\
\hline y-dimension & $80 \mathrm{~m}$ & $\mathrm{k}_{\mathrm{v}}$ & $800 \mathrm{mD}$ \\
\hline z-dimension & $19.6 \mathrm{~m}$ & & \\
\hline well length & $800 \mathrm{~m}$ & & \\
\hline \multicolumn{2}{|c|}{ Reservoir Properties } & \multicolumn{2}{|c|}{ Oil Properties } \\
\hline initial pressure & $2,654 \mathrm{kPa}$ & components & water, oil, and gas \\
\hline initial temperature & $16^{\circ} \mathrm{C}$ & $\begin{array}{l}\text { initial } \\
\text { composition }\end{array}$ & $90 \%$ (mole) oil \\
\hline initial $S_{o}$ & $85 \%$ & & $10 \%$ (mole) gas \\
\hline initial $S_{w}$ & $15 \%$ & $\begin{array}{l}\text { viscosity } \\
\text { (mPa-s) versus } \\
\text { temperature }(\mathrm{K}) \\
\text { function }\end{array}$ & $\mu=1.74 \times 10^{-6} \exp \frac{6232.74}{T}$ \\
\hline
\end{tabular}

Table 2: Operating conditions for early-time performance study.

\begin{tabular}{|l|c|c|c|c|}
\hline \multicolumn{1}{|c|}{ Property } & \multicolumn{4}{|c|}{ Operating Condition } \\
\hline $\begin{array}{l}\text { steam } \\
\text { temperature } \\
\left({ }^{\circ} \mathrm{C}\right)\end{array}$ & SAGD & Extreme & Cyclic & Circulating \\
\hline $\begin{array}{l}\text { max. injection } \\
\text { rate }(\mathrm{CWE} \\
\left.\mathrm{m}^{3} / \text { day }\right)\end{array}$ & 295 & 295 & 295 & 295 \\
\hline $\begin{array}{l}\text { max. injection } \\
\text { pressure }(\mathrm{kPa})\end{array}$ & 10,000 & 10,000 & 10,000 & 300 \\
\hline $\begin{array}{l}\text { max. } \\
\text { production } \\
\text { rate }\left(\mathrm{m}^{3} \text { /day) }\right.\end{array}$ & 300 & 600 & 300 & 300 \\
\hline $\begin{array}{l}\text { min. production } \\
\text { pressure (kPa) }\end{array}$ & 500 & 500 & 500 & 500 \\
\hline
\end{tabular}


Table 3 Description of sensitivity analysis.

\begin{tabular}{|c|c|c|}
\hline \multirow[t]{2}{*}{ Property } & \multicolumn{2}{|c|}{ Operating Condition } \\
\hline & Initial Cyclic & SAGD \\
\hline $\begin{array}{l}\text { steam } \\
\text { temperature }\left({ }^{\circ} \mathrm{C}\right)\end{array}$ & 295 & 238 \\
\hline maximum injection rate (CWE $\mathrm{m}^{3} /$ day) & 300 & 200 \\
\hline maximum injection pressure $(\mathrm{kPa})$ & 8000 & 3230 \\
\hline maximum production rate $\left(\mathrm{m}^{3} /\right.$ day $)$ & 300 & 300 \\
\hline minimum production pressure $(\mathrm{kPa})$ & 2230 & 500 \\
\hline \multicolumn{3}{|l|}{ Oil Viscosity } \\
\hline $\begin{array}{l}\text { 20,000 mPa-s case } \\
(\mu(\mathrm{mPa}-\mathrm{s}), \mathrm{T}(\mathrm{K}))\end{array}$ & \multicolumn{2}{|c|}{$\mu=8.61 \times 10^{-6} \exp \frac{6232.74}{T}$} \\
\hline $\begin{array}{l}\text { 40,000 mPa-s case } \\
(\mu(\mathrm{mPa}-\mathrm{s}), \mathrm{T}(\mathrm{K}))\end{array}$ & \multicolumn{2}{|c|}{$\mu=1.72 \times 10^{-5} \exp \frac{6232.74}{T}$} \\
\hline
\end{tabular}

Table 4 Parameters used to calculate $t_{v} / t_{h}$.

\begin{tabular}{|c|r|}
\hline Parameter & \multicolumn{2}{|c|}{ Value } \\
\hline $\mathrm{h}$ & $19.6 \mathrm{~m}$ \\
\hline $\mathrm{L}$ & $30 \mathrm{~m}$ \\
\hline $\mathrm{k}_{\mathrm{h}}$ & $3400 \mathrm{mD}$ \\
\hline $\mathrm{k}_{\mathrm{v}}$ & $800 \mathrm{mD}$ \\
\hline $\mathrm{p}_{\text {inj }}$ & $3230 \mathrm{kPa}$ \\
\hline $\mathrm{p}_{\text {prod }}$ & $2230 \mathrm{kPa}$ \\
\hline oil density & $950 \mathrm{~kg} / \mathrm{m}^{3}$ \\
\hline steam density & $42.6 \mathrm{~kg} / \mathrm{m}^{3}$ \\
\hline $\mathrm{g}$ & $9.8 \mathrm{~m} / \mathrm{s}^{2}$ \\
\hline
\end{tabular}




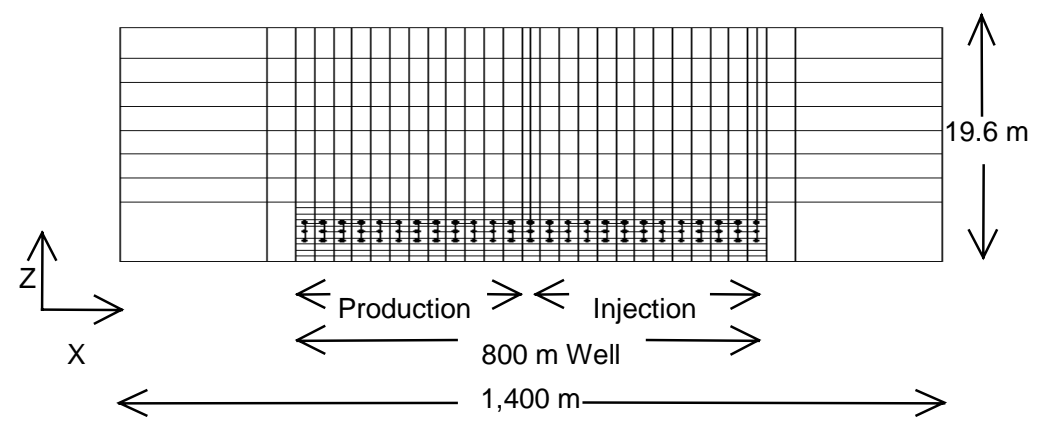

(a)

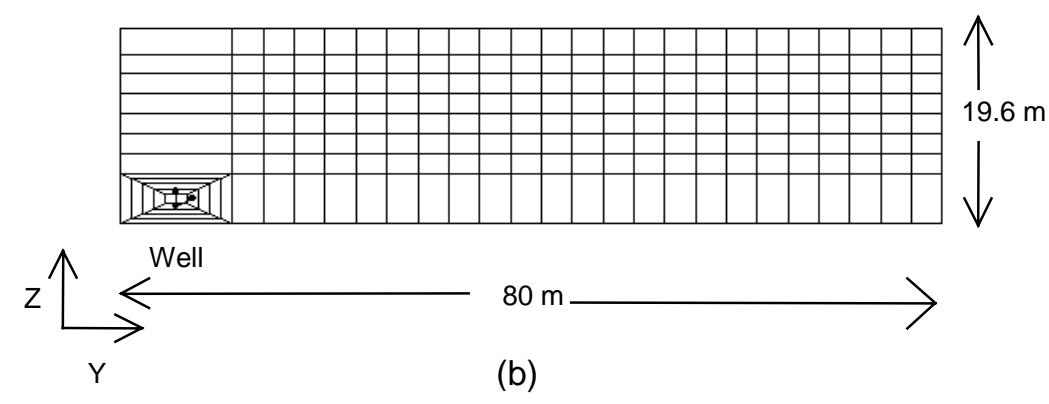

Figure 1: Schematic of grid system: (a) parallel to well bore and (b) perpendicular to wellbore. 


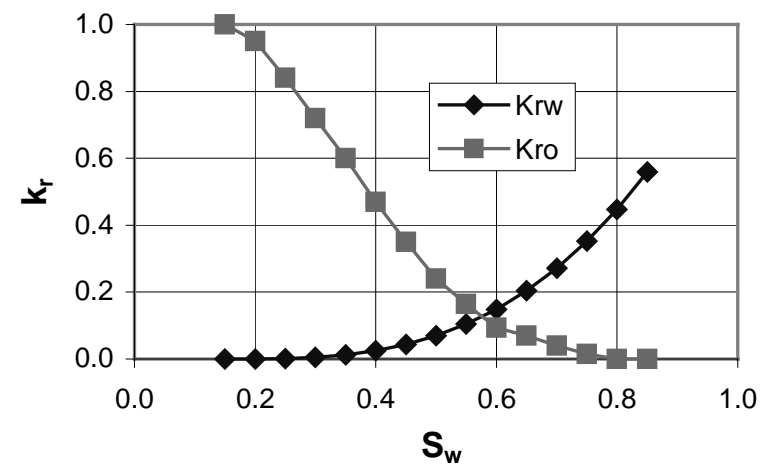

Figure 2: Water-oil relative permeability function.

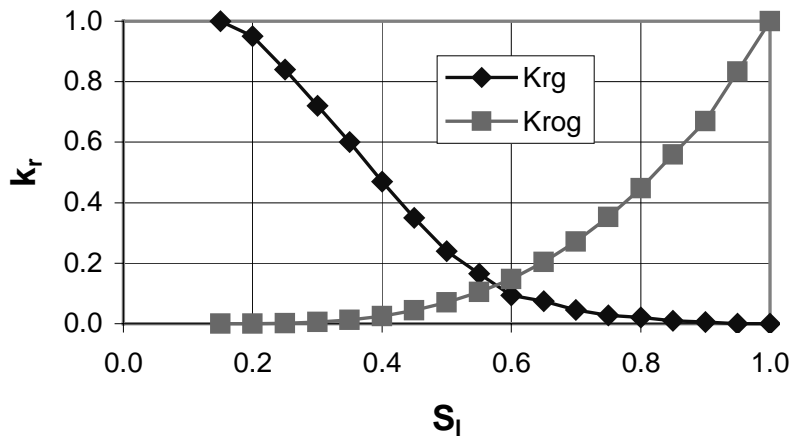

Figure 3: Gas-liquid relative permeability function. 

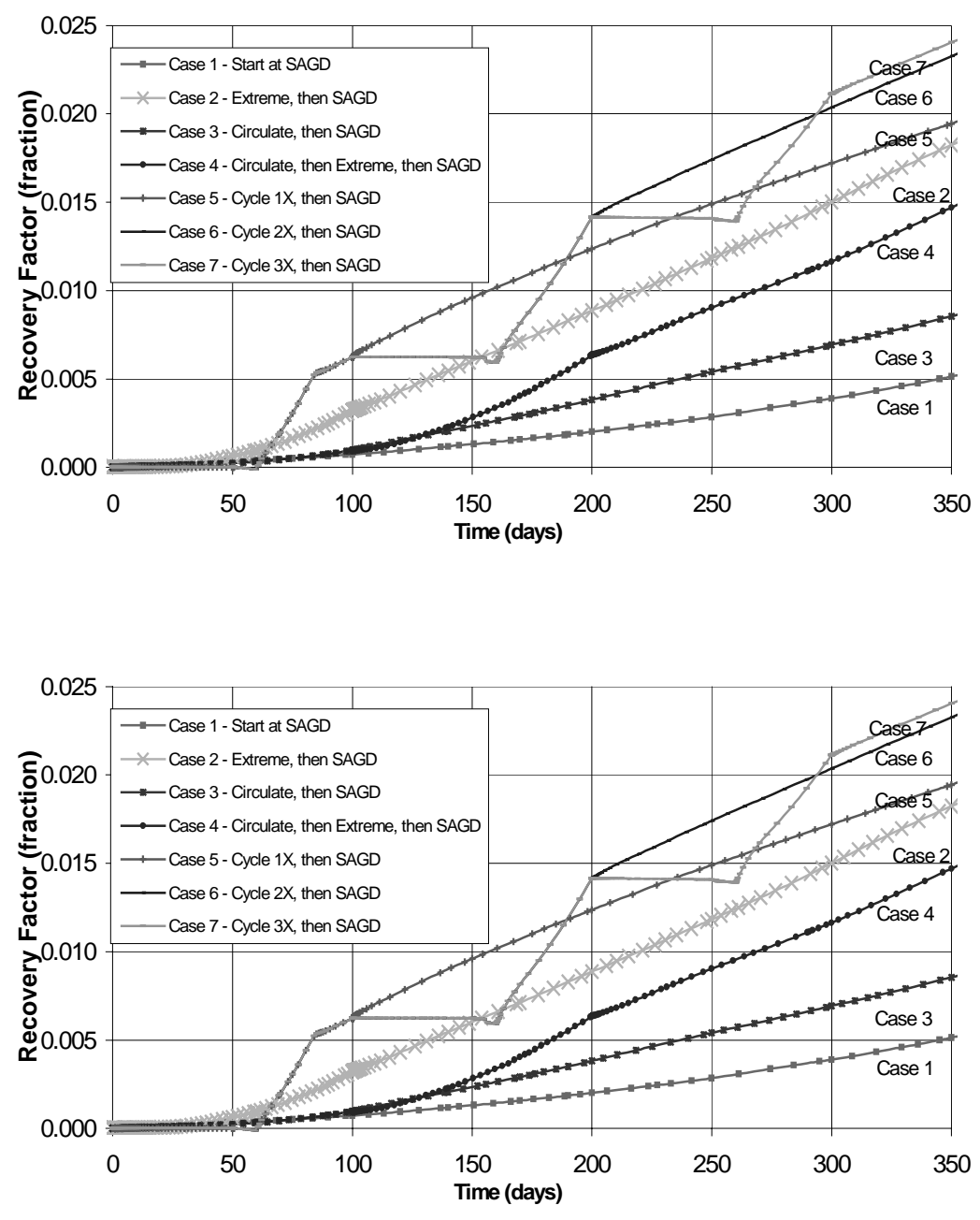

Figure 4: Recovery factor for the first year of production. 


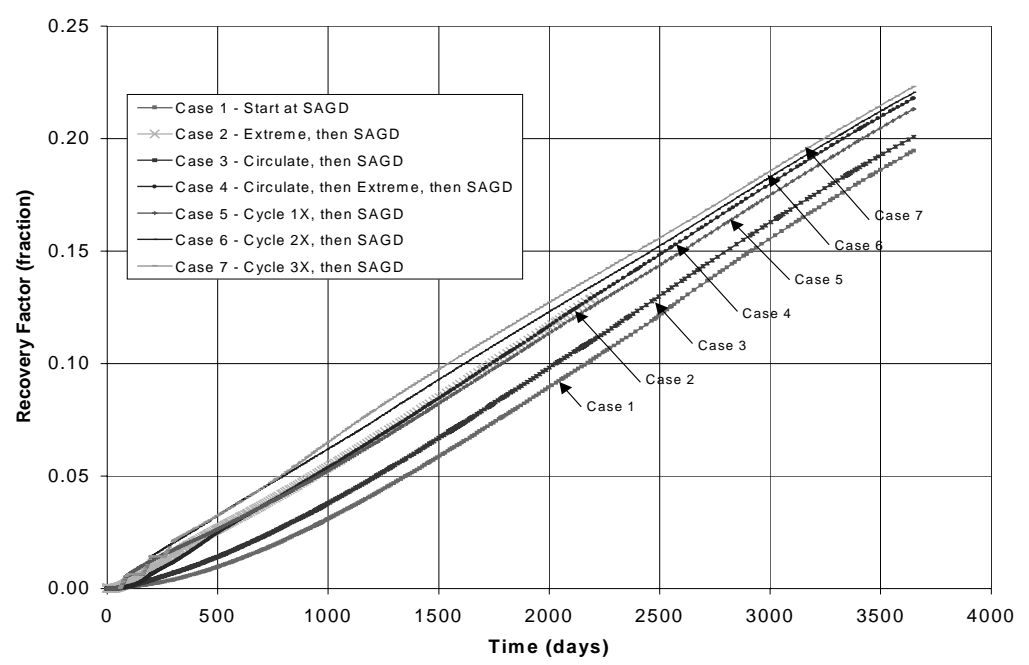

Figure 5: Recovery factor for 10 years of production.

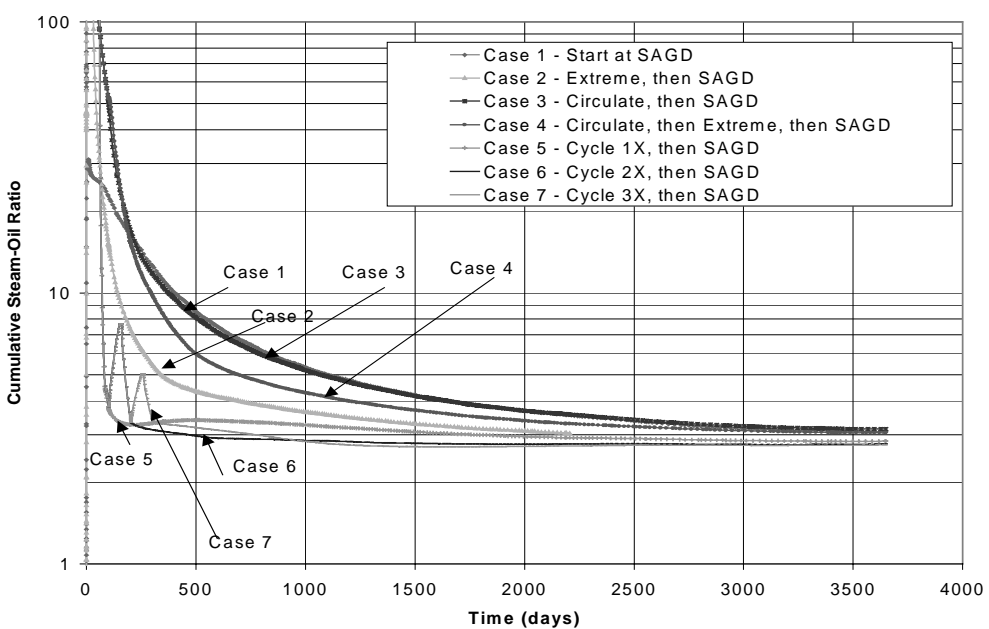

Figure 6: Cumulative steam oil ratio for 10 years of production. 


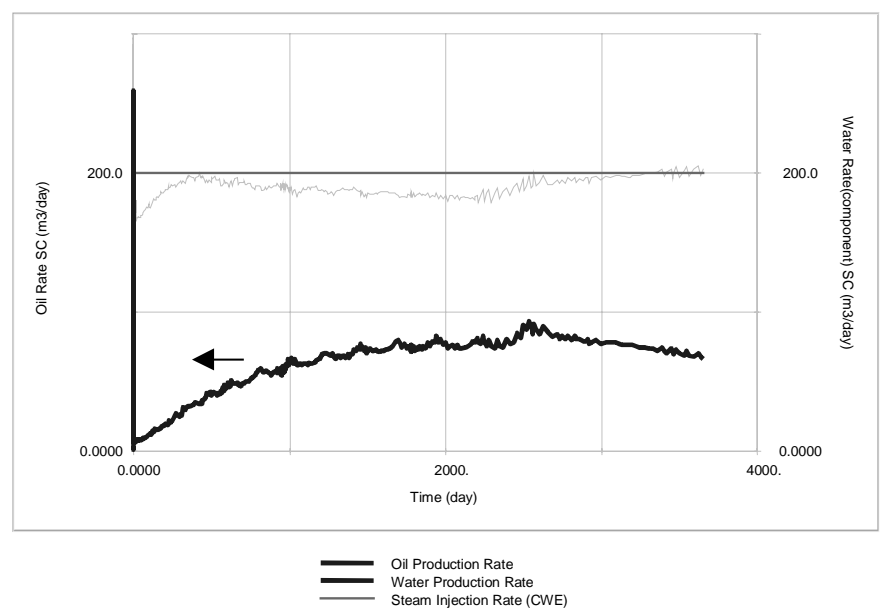

Figure 7: Steam injection and production history, SAGD from start-Case 1.

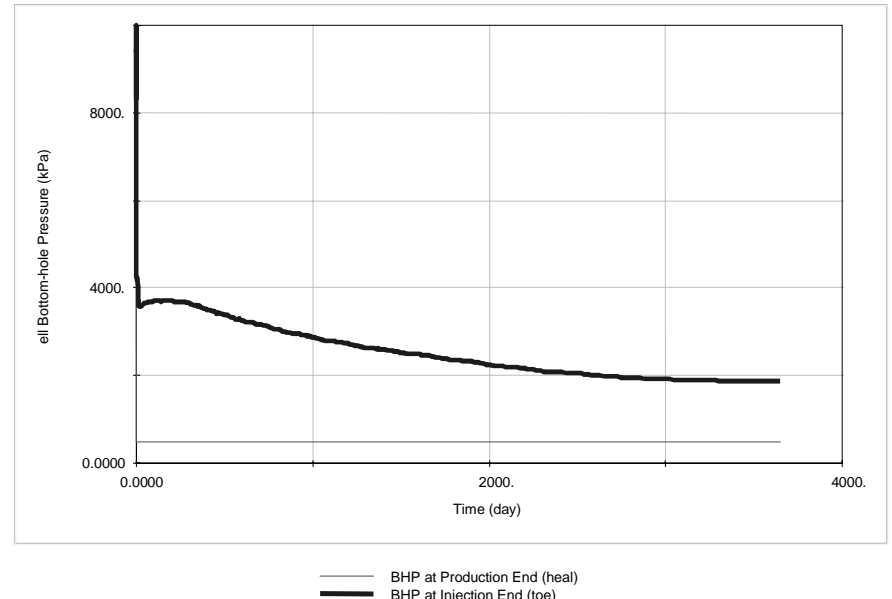

Figure 8: Bottomhole pressure, SAGD from start-Case 1. 


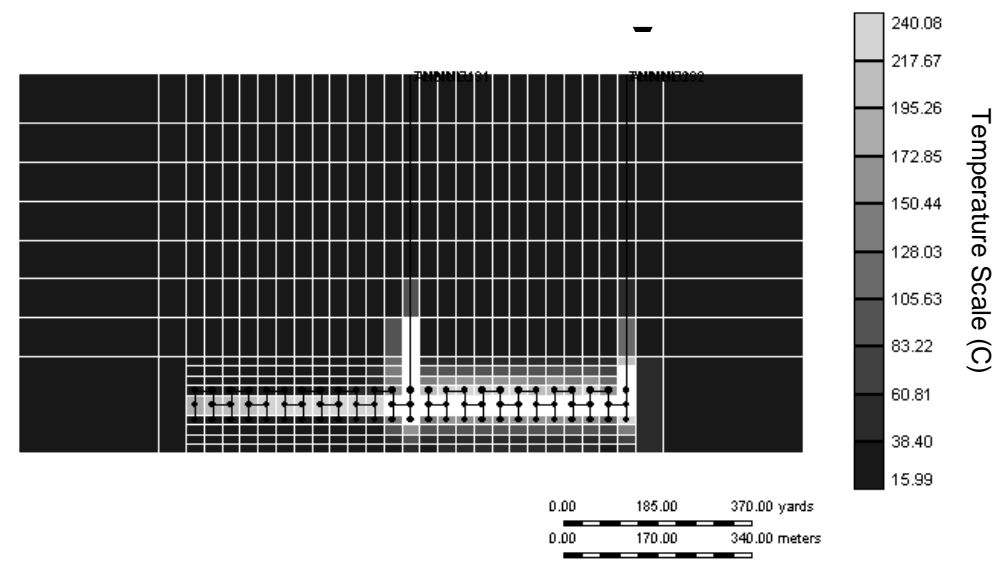

Figure 9: Temperature profile at 100 days, SAGD from start-Case 1.

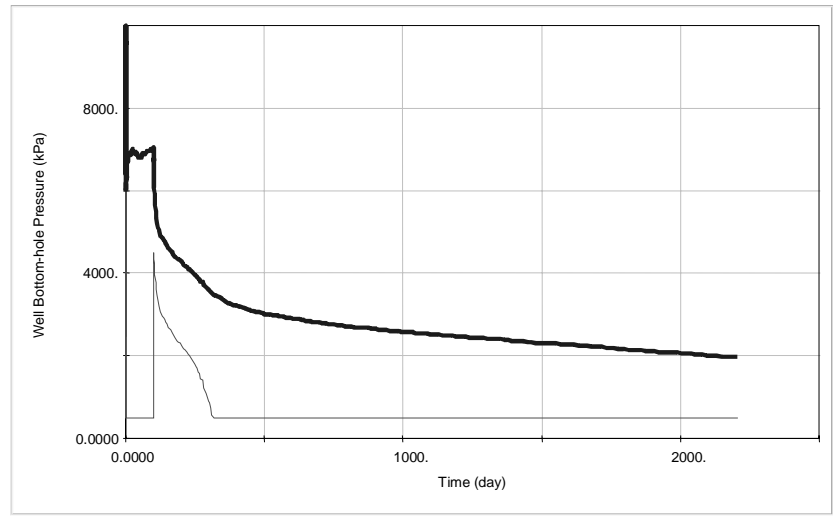

BHP at Production End (heel)

Figure 10: Bottom-hole pressure, extreme pressure differential then SAGD-Case 2. 


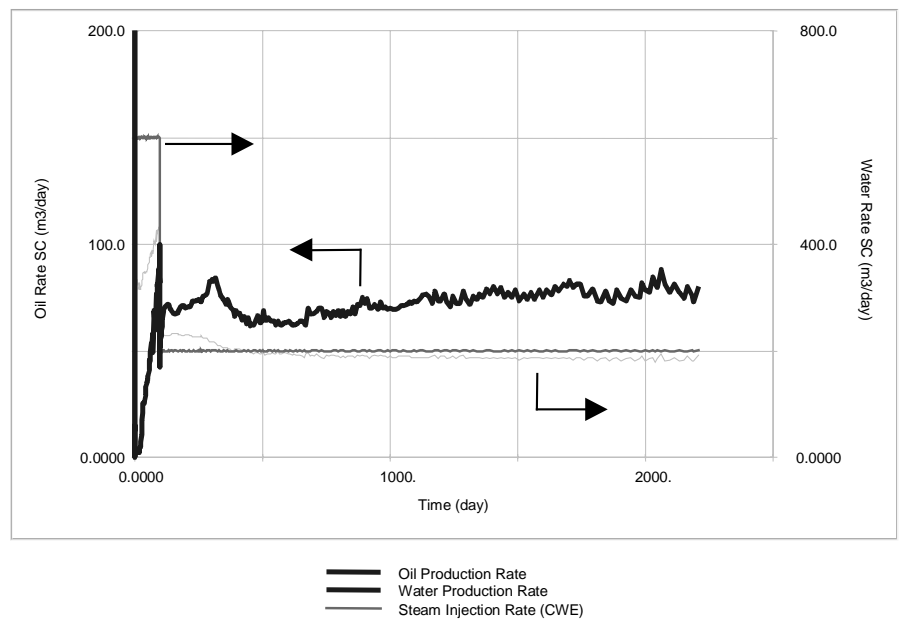

Figure 11: Steam injection and production history, extreme pressure differential then SAGD-Case 2.

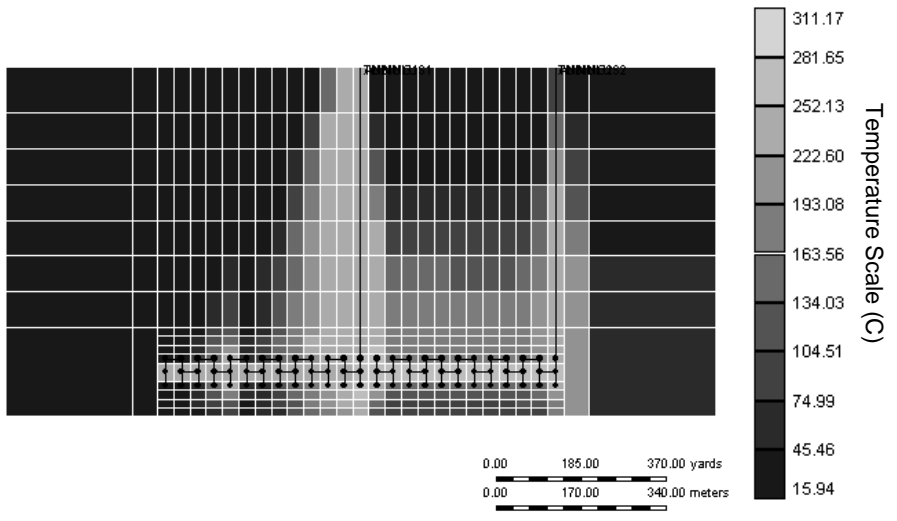

Figure 12: Temperature profile at 200 days, extreme pressure differential then SAGD-Case 2. 


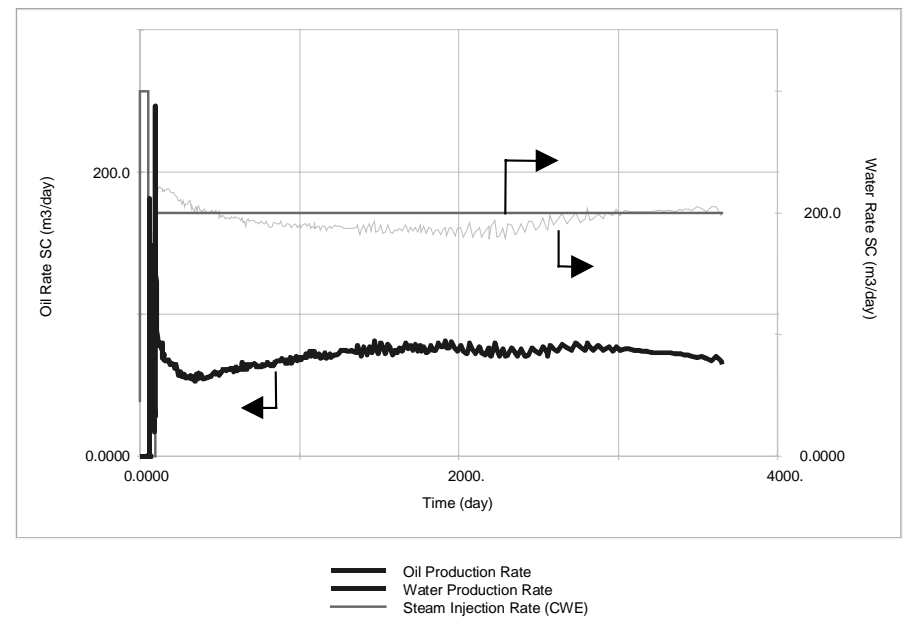

Figure 13: Steam injection and production history, 1 cycle then SAGD-Case 5.

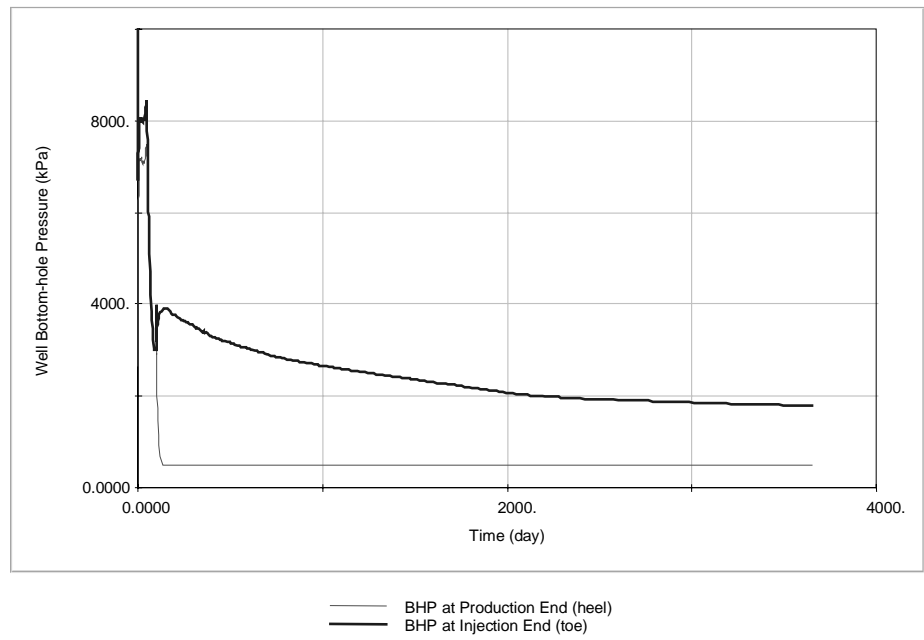

Figure 14: Bottomhole pressure, 1 cycle then SAGD-Case 5. 


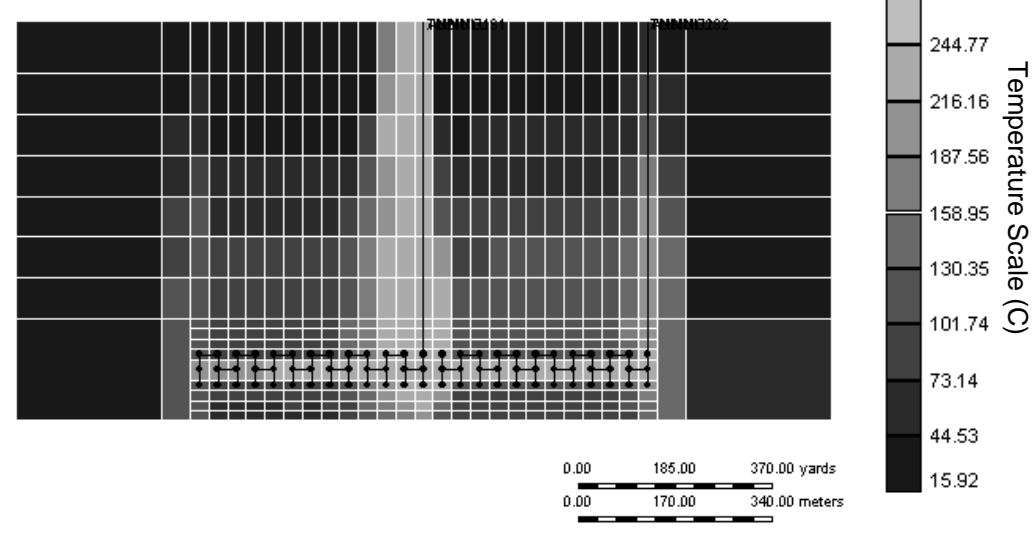

Figure 15: Temperature profile at 200 days, 1 cycle then SAGD-Case 5.

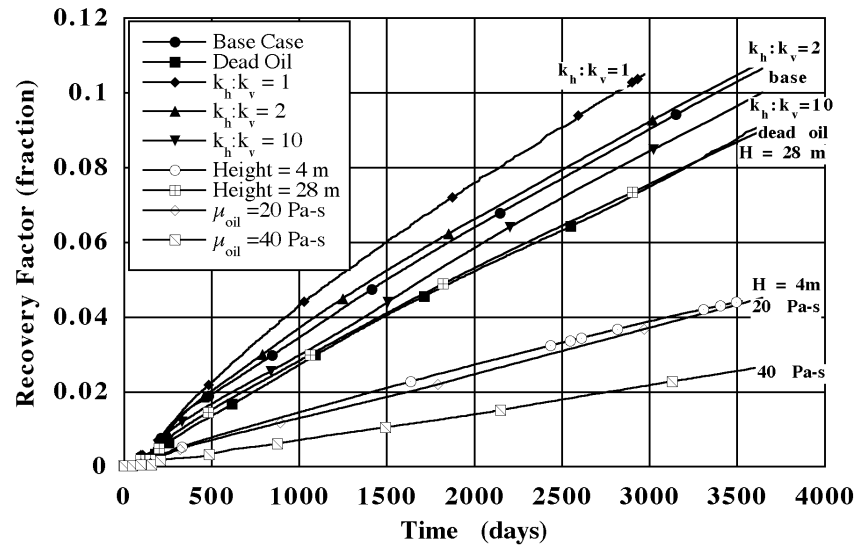

Figure 16: Recovery factor versus time, sensitivity analysis. 


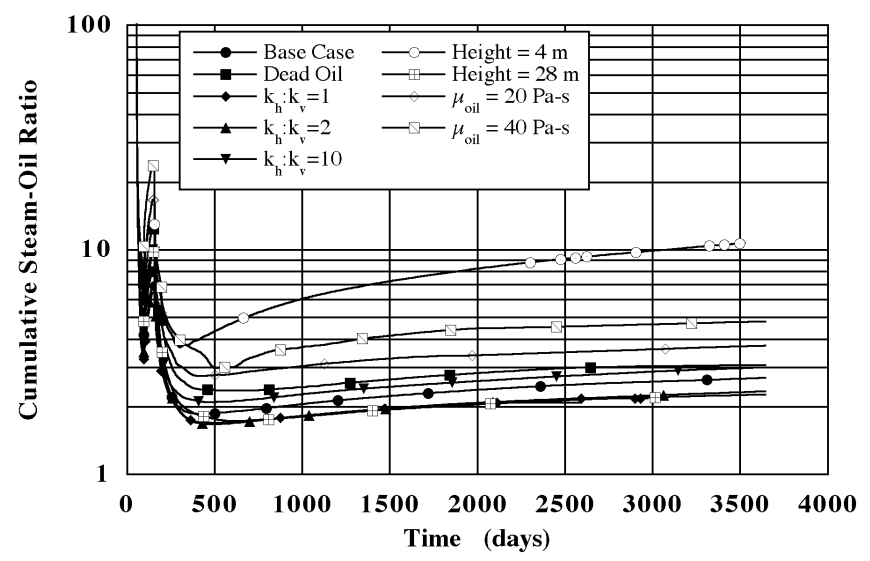

Figure 17: Cumulative steam oil ratio, sensitivity analysis.

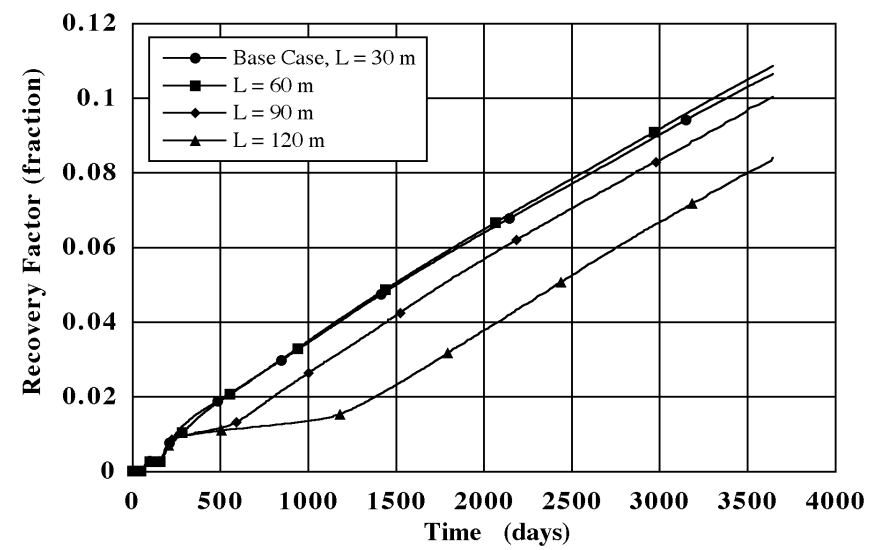

Figure 18: Recovery factor versus time, effect of injector to producer section spacing. 


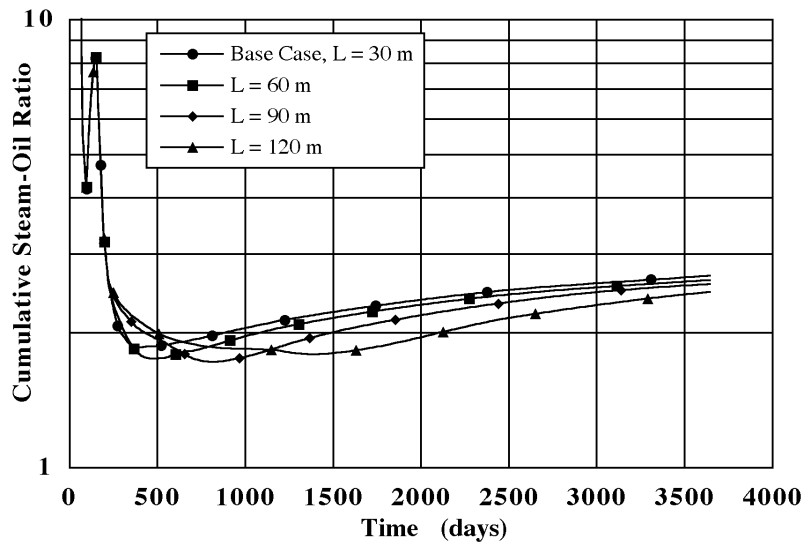

Figure 19: Cumulative steam-oil ratio, effect of injector to producer section spacing. 